\title{
Analysis on Operation Management of Hunan Kingyang Distribution Center
}

\author{
Shijun Yuan \\ Hunan Modern Logistics College \\ Changsha, China
}

\author{
Jianhua Chen \\ Hunan Modern Logistics College \\ Changsha, China
}

\begin{abstract}
In order to ensure that the Hunan Kingyang Distribution Center achieves the expected goals, this paper conducts research from the aspects of operation preparation, project operation and management, and marketing plan.
\end{abstract}

Keywords-distribution center; operation management; marketing plan

\section{INTRODUCTION}

On the basis of the expected effect of the preliminary infrastructure construction, the Kingyang Distribution Center in Hunan will further promote the project construction and smoothly realize the economic efficiency objectives in the feasibility study. It is necessary to analyze and organize the running and management of the project of the distribution center from the aspects of operation preparation, project management and management, marketing plan, etc.

\section{THE OPERATION PREPARATION}

\section{A. Basic Principles of Preparation}

First, the preparation for the operation of the project is carried out simultaneously with the construction of the project, and the work is coordinated during the operation.

Second, the scale and input of the project are in line with the scale of the project, including the number of preparatory people and the basic quality, which are compatible with the scale of the distribution center project and the number of people necessary for the opening of the project.

\section{B. Basic Tasks of Preparation}

First, do a good job in market positioning for the distribution center, propose the logistics function requirements of the center, and feedback the results of the positioning to the project planning, design and construction activities, so that the hardware construction of the project meets the functional requirements.

Second, according to the results of market positioning and the design of the project, plan the logistics products of the distribution center.

Third, design logistics processes for various products according to the product planning of the distribution center.
Fourth, according to the requirements of product planning and logistics processes, propose the planning of supporting facilities in the distribution center, and organize and improve supporting facilities.

Fifth, according to the logistics function, product planning and logistics process of the center, the establishment plan of the central organization is proposed. After review and determination by the company's power department, the organization of the operation of the distribution center is set up

Sixth, provide employees according to the needs of preparation and opening, and conduct pre-job training for employees according to the product planning, logistics operation procedures and operational rules of the distribution center.

Seventh, according to market positioning, screen target customers, develop service plans, and conduct marketing previews for target customers.

Eighth, the organization opened. After the completion of the preparatory work, the distribution center will be organized in time for opening.

\section{Market Positioning Work}

First, according to the development of the national economy and the development of the logistics industry in Changsha, the conceptual orientation before the project is established, which will provide direction for further positioning investigation.

Second, selectively conduct on-the-spot investigation, investigation, analysis, research, and evaluation of logistics functions, technical features, hardware construction, and market positioning of existing logistics parks.

Third, study the logistics status of Changsha in the economic operation process of the above-mentioned economic circle by studying the Pan-Pearl River Economic Circle, the economic circle along the Beijing-Guangzhou line, and the logistics demand and logistics structure along the Yangtze River Economic Circle.

Fourth, investigate the situation of the economic development zone within 50 kilometers around the distribution center, especially the type of enterprise, logistics characteristics, and existing logistics supply. 
Fifth, evaluate the company's logistics technology and logistics tools, and comprehensively evaluate the company's logistics supply capabilities.

Sixth, based on the above work, make the market positioning of the distribution center, draw conclusion, and make confirmation through appropriate procedures.

Seventh, the results of the market positioning will be implemented in the construction process of the project, and the project planning, design, construction and preparation operations will be organized.

\section{Product Planning}

First, evaluate the basic logistics environment of the distribution center according to the geographical conditions of the distribution center.

Second, evaluate the logistics functions that the hardware can support according to the scale and design of the distribution center.

Third, assess the company's actual logistics operations according to the company's existing financial strength, business model and business value.

Fourth, evaluate the depth and level of logistics needs based on the results of the survey of logistics market needs.

Fifth, design logistics product types based on the above factors.

\section{E. Process Design}

First, comprehensively analyze the process experience of company's existing logistics business.

Second, comprehensively consider the needs of logistics products for logistics processes.

Third, comprehensively analyze the maturity of the new electronic information technology in the market, application costs and the application prospects in the distribution center business in the near and long term.

Fourth, comprehensively assess the actual operational capabilities of the workforce and the potential for improvement and improvement in the near future.

Fifth, comprehensively assess the financial consequences and near-and-far-term status of various logistics equipment used in logistics operations.

Sixth, integrate the above factors to design the logistics process.

\section{F. Organizational Construction}

To establish a complete organization for the opening and operation of the distribution center, the following factors should be considered comprehensively:

First, the current organization of Kingyang Logistics Company; second, new logistics functions for the organization; third, the adjustment and change of the operation mode brought about by the introduction of new investors in the distribution center project.

\section{G. Job Setting and Recruitment}

First, plan the specific positions and number of positions, so as to propose the talent recruitment needs according to the distribution center logistics function, product planning, business process, and organization setting.

Second, propose recruitment requirements and standards for talents in different positions.

Third, develop a recruitment process to ensure fairness and justice of recruitment as well as the result.

\section{H. Training}

Pre-employment training should be organized for newly recruited employees and original employees of companies that intend to adjust to the distribution center. The training includes:

First, basic understanding of the logistics industry; second, basic understanding of Kingyang Logistics Company; third, basic understanding of the Kingyang Distribution Center; fourth, basic understanding of the logistics function, business model, logistics value and product structure of Kingyang Distribution Center; fifth, in-depth training in logistics project processes; sixth, in-depth training on marketing concepts and marketing methods; seventh, basic logistics technology and operation of logistics facilities; eighth, business technical points of each position.

\section{PROJECT OPERATION AND MANAGEMENT}

\section{A. Business Philosophy}

- To be faithful and benevolent;

- to prosper family and create career;

- to be truth-seeking and pragmatic;

- to be innovative and pioneering.

\section{B. Business Purposes}

Realize value, create value, and discover value.

\section{Business Model}

The project center had nearly 10 years' experience in thirdparty logistics, and it successfully explored and summarized the operation mode suitable for third-party logistics operations, called "contract management, industry alliance, informationdriven, product operation". After the establishment of the Kingyang distribution center, the business model will be further upgraded to "contract management, industry alliance, information-driven, base support, product operation, and integrity development".

First, different from the traditional management of logistics operations, the focus of business management is raised to logistics contract management. The logistics operation method is dwarfed into part of the enterprise logistics resources, and such resources are not necessarily held by the logistics enterprises, and can be collected from the society according to the principle of marketization. Comprehensive management of 
logistics service contracts has become the focus of logistics management.

Second, within the scope of logistics activities, establish a close logistics cooperation partnership with logistics partners. Ensure that when the company obtains a logistics contract, the logistics contract can be operated and completed within the collaborative system.

Third, develop and establish a logistics information system that meets the needs of logistics operations, realize the information interface between the company, the company and customers, and the company and the cooperation company, and build a smooth, orderly and efficient logistics operation process.

Fourth, establish a fairly large-scale distribution center as the base of the company's logistics operation, form a regional logistics node, so that it can collect goods and bulk goods to support the operation of the entire logistics system and ensure the stable development of the logistics business.

Fifth, supported by the base, realize the logistics operation product management. The company's various logistics services will be standardized to meet the logistics needs of different customers in different markets.

Sixth, implement integrity-based logistics services, and establish an honest operating system and cooperation alliance, so that logistics activities will always be in a sustainable state of development.

\section{The Marketing Plan}

1) Marketing strategy: First, marketing activities should be oriented to the needs of the logistics market. First, a special marketing research institution is set up within the enterprise to timely understand, analyze and judge the dynamics of the logistics market. Second, the decision-making consultation mechanism is introduced, and experts, scholars and relevant persons from the logistics industry and the government economic authorities are hired to act as consultants of the company to seek external decision support; the third is to establish a regular market analysis system, regularly making analysis for the logistics market.

Second, proper professional guidance should be given on market demand. On the one hand, take active measures to improve the enterprise's logistics decision-making and consulting capabilities as soon as possible; on the other hand, take effective measures to stimulate the potential logistics demand of the market and externalize into a realistic thirdparty logistics demand, and improve the market depth of logistics demand.

Third, the marketing concept should be formed in all employees. The marketing organization of an enterprise must increase marketing efforts and improve marketing efficiency. All departments and all personnel of the company need to establish marketing awareness, integrate marketing concepts into all work of the company, and externalize the results of internal operations of the company into the image of honesty, quality and efficiency in the eyes of customers.
Fourth, professional marketing is required for targeted customers. On the basis of professional planning, make specialized operation to form a professional logistics solution, and repeatedly negotiate and communicate with customers, fully demonstrate the logistics professional level and logistics industry spirit, and spread the enterprise spirit and the way of doing business in the practice of exhibition industry and marketing.

Fifth, highlight the resource and technological advantages of the company and actively create conditions to participate in market competition.

2) Market operation ideas: First, highlight the advantages of the base. The Kingyang Distribution Center is the foundation platform that supports the entire operating system of the Kingyang Distribution Center. In operation, it will form four major advantages: First, management and technology. Second, the transportation. the distribution center takes the advantages of highway, railway, water transportation and air transportation, which will inevitably attract the attention of the majority of logistics demanders; the third is the storage, the logistics environment is unparalleled; the fourth is the logistics market, after the operation of the center, it will attract other logistics companies to join the operation, and in the long-term, it will form a logistics supply market centered on Kingyang enterprises.

Second, stabilize old customers. Some old customers who have long-term cooperation with Kingyang have established close interdependence in long-term cooperation. This is the customer base that the distribution center can rely on. The distribution center should further consolidate the cooperation relationship with these old customers. With the improvement of the basic conditions, the center should further expand cooperation with them. The loss of business caused by the limitations of the basic conditions will gradually return due to the completion of the base.

Third, develop of new large customers with target. The logistics demand of large customers is generally very large, but the logistics technology requirements are also very high. The company will develop according to its own resource conditions and develop to ensure operate well and stably.

Fourth, establish a mechanism to guide the logistics of SMEs, so as to achieve the integration of SME logistics needs. The first is to clearly mark the price so that SMEs can determine the logistics cost without contacting them. The second is to open the operation and open the logistics operation rules and operation procedures to the market, so that SMEs do not need to make an appointment or sign an agreement in advance when they need logistics. It can obtain logistics services directly; the third is to expand the network, further improve the logistics distribution system within the province, and extend the base service to all parts of the province to facilitate SME customers.

\section{3) Pricing principles:}

a) Cost principle: there is a certain cost for any logistics operation. The price should not be determined lower than the 
operating cost and the reasonable profit should be properly considered.

b) Market principle: The logistics price should be based on the current market price and cannot be deviated too far.

c) The value principle: For businesses that do not have a market reference price, they should scientifically evaluate the value creation capability of logistics operations and price them based on the actual value created.

d) Strategic coordination principle: The price should be set in line with the company's development strategy.

4) Sales team construction: First, according to the characteristics of the industry market, rationally set up marketing organization and management mode.

Second, priority is given to recruiting marketing professionals with professional background and high quality;

Third, prepare marketing personnel training courses from company system, product, marketing theory, customer relationship, market overview, customer system and basic finance, regular training for marketing personnel, or inviting external professionals to do special lectures and targeted training.

Fourth, pay attention to the monitoring and management of marketing personnel, and improve the marketing management system in performance appraisal, award and punishment, customer data and sales performance.

Fifth, retain the mechanism of benign communication within the marketing staff to promote each other and improve the overall business development level of the department.

Sixth, provide employees with maximum capacity and personal development space to maintain a relatively stable marketing team.

Seventh, provide opportunities for marketing personnel with external training opportunities at the right time.

\section{CONCLUSION}

In addition to doing a good job in the above aspects, Hunan Kingyang Distribution Center project operation management needs further plan and implement specific plans in various areas such as project operation team formation, investment and financing analysis, etc., to ensure that project operation meets expected aims. It can be foreseen that the construction of Hunan Kingyang Distribution Center will play a positive role in promoting the development of regional economy and the improvement of the level of consumer logistics services for urban and rural residents.

\section{REFERENCES}

[1] Li Yuan'ai. On the Development Strategy of Urban Logistics Distribution in China[J].Logistics Technology. 2015(04). (in Chinese)

[2] Zhao Chuang, Liu Kai, Li Diansheng. Risk Analysis and Management of Logistics Park Construction[J].China Civil Engineering Journal. 2004(12). (in Chinese)

[3] Xi Chongbin. Understanding the operation and management of logistics center [J].LogisticsTechnology and Application. 2014(06). (in Chinese) 